\title{
HIV Pre-exposure Prophylaxis: Characterization and Adherence of Users at Risk of Infection
}

\author{
Francisco Álisson Paula de França ${ }^{1, *}$, Ana Claudia de Brito Passos², Melissa Soares Medeiros ${ }^{3}$, Marta Maria de França Fonteles \\ 'Department of Pharmacy, Graduate Program in Pharmaceutical Sciences, Federal University of Ceará, Fortaleza, Ceará, BRAZIL. \\ 2Department of Pharmacy, Group for the Prevention of Drug Misuse, Federal University of Ceará, Fortaleza, Ceará, BRAZIL. \\ ${ }^{3}$ São José Hospital for Infectious Diseases, State Health Department of Ceará, BRAZIL.
}

\begin{abstract}
Objectives: To delineate the sociodemographic and clinical characteristics, sexual behavior, and the degree of adherence of users to Human Immunodeficiency Virus (HIV) Pre-Exposure Prophylaxis (PrEP), as well as the factors that impact their full adherence. Materials and Methods: This is an analytical, cross-sectional, retrospective study carried out in reference services in infectology. Subjects with at least three clinical monitoring of PrEP were included in the study. We considered as 'full adherence' those individuals who took $100 \%$ of the recommended doses. Bivariate and multivariate analysis was performed to investigate the association between full adherence to PrEP and selected variables. Results: Most participants were male $(80.1 \% ; n=185)$, homosexual $(61.9 \% ; n=143)$, with a mean age of $32 \pm 8.6$ years. Regarding the clinical aspects, the presence of subjects with chronic kidney disease using prophylaxis drew attention. Concerning the use of PrEP, only 5.6\% $(n=13)$ had a degree of adherence lower than $80 \%$. In this context, it was observed that user characteristics, such as meretriciousness and homosexuality, impacted full adherence to the method ( $p=0.033 ; p=0.049$, respectively). Conclusion: The results
\end{abstract}

achieved pointed to high adherence to PrEP. However, it was observed that factors such as homosexuality and prostitution had a negative association with widespread adherence to prophylaxis. In this sense, clinical follow-up by a multidisciplinary team is essential, given the need to adopt strategies to strengthen the use of prophylaxis by specific groups and the existence of patients with clinical conditions that the use of PrEP can aggravate. Key words: Antiretrovirals, Communicable Disease Control, Pre-Exposure Prophylaxis, HIV, Men who have Sex with Men.

Correspondence

Francisco Álisson Paula de França,

Department of Pharmacy, Graduate Program in Pharmaceutical Sciences, Federal University of Ceará, Fortaleza, Rua Alexandre Baraúna, 949 - Rodolfo Teófilo, Ceará, BRAZIL.

Email id: alissonpetunifor@gmail.com

DOI: 10.5530/jyp.2022.14.18

\section{INTRODUCTION}

Pre-Exposure Prophylaxis (PrEP) for the prevention of Human Immunodeficiency Virus (HIV), the cause of Human Immunodeficiency Syndrome (AIDS), has evolved significantly from the initial conceptualization of protection tested in animal models, following evidence of prevention using antiretrovirals (ARV) for occupational and non-occupational post-exposure prophylaxis. Since then, clinical trials have demonstrated the effectiveness of oral PrEP, with evidence from studies showing that PrEP significantly reduced the risk of HIV acquisition. However, the level of effectiveness varied according to differences in adherence among study populations, such as in Men who have Sex with Men (MSM), showing higher levels of effectiveness than found in women-only studies. ${ }^{1}$ Thus, adherence is a central component in considering program planning, budgeting, and effectiveness of PrEP. ${ }^{2}$ The primacy of a combined effort, including early ARV treatment for People Living with HIV (PLHIV), rendering them non-infectious, and effective prevention interventions for people not carrying the virus, including condom distribution, treatment of Sexually Transmitted Infections (STI), post-exposure prophylaxis and oral PrEP, voluntary medical male circumcision, as well as ongoing outreach and educational programming, are necessary for the achievement of the World Health Organization (WHO) goal related to global control of the epidemic by $2030 .{ }^{3}$ The WHO and the Joint United Nations Programme on HIV/AIDS (UNAIDS) have made PrEP implementation a priority for populations at "substantial risk", ${ }^{4}$ and several countries have developed national guidelines and plans integrating PrEP into programming, with the United States, South Africa, and Kenya among the first with official government-supported guidance., ${ }^{5,6}$ These guidelines were developed based on the evidence that PrEP is the most effective way to control the epidemic. These guidelines were developed based on evidence from demonstration projects. ${ }^{2,7}$

Thus, this measure is at the center of debates about the new possibilities of HIV prevention, increasing optimism about the control of the global epidemic, through the combination of two ARV, such as tenofovir (TDF) associated with emtricitabine (FTC), meeting sexual practices, with a degree of protection of $96 \%$ (90\% to $>99 \%$ ), when used daily. ${ }^{8,9}$

In Brazil, PrEP was incorporated into the Unified Health System (SUS) in late 2017, based on the public consultation conducted by the National Committee for Incorporation of Technologies into the Unified Health System (CONITEC), which provided an opportunity for the manifestation of entities and bodies external to the Ministry of Health (MS) to draft what is now the Clinical Protocol and Therapeutic Guidelines for Pre-Exposure Prophylaxis at Risk for HIV Infection (PCDT-PrEP). ${ }^{8}$

Considering this context, the medicines that constitute PrEP were incorporated into the National List of Essential and Strategic Medicines $(\mathrm{RENAME})^{10}$ of the MS, in the Strategic Component of Pharmaceutical Assistance (CESAF), aiming to serve specific populations, such as gay men and other MSM, transgender people, sex workers, and serodiscordant couples, being necessary that these populations fit at least one of the following criteria: a) frequent search for HIV Post-Exposure 
Prophylaxis (PEP); b) recurrent STI episodes; c) sexual intercourse with PLHIV without the use of condoms, considering that the population segments pointed out have up to 40 times higher risk of becoming infected by HIV when compared to the general population. ${ }^{8}$

However, one of the initial concerns for PrEP implementation is, until today, related to sexual practices without the use of condoms, since PrEP has protection only against HIV and is not effective in preventing other STI. However, results from The Pre-exposure Prophylaxis Initiative Trial (iPrEx), the first large clinical trial of PrEP conducted on more than two continents, suggested no significant differences in condom use between PrEP and control groups in MSM. ${ }^{11,12}$

As PrEP is a recently implemented technology, it is relevant to update the scenario involving this technology to know the behavior and characteristics of users, the level of adherence to prophylaxis, and the aspects that may influence the success of the method.

In this sense, the present study aimed to delineate the sociodemographic and clinical characteristics, sexual behavior, the degree of adherence of users to PrEP, and the factors that impact their full adherence.

\section{MATERIALS AND METHODS}

It is an analytical, retrospective, cross-sectional study with a quantitative approach. Secondary data collection occurred during August and September 2020 through the System for Logistic Control of Medications (SICLOM), accessed at the Coordination of Pharmaceutical Assistance (COASF), an agency linked to the Secretariat of Health of the State of Ceará (SES-CE).

The study population consisted of all users registered in SICLOM and using PrEP, assisted in three specialized infectious diseases services of a northeastern Brazilian state, from December 2017 to June 2020. The study included duly registered users aged 18 years or older who had at least three follow-up consultations, which was necessary for minimal data collection. We excluded users with suspected immunological window, inconclusive or confirmatory rapid or laboratory tests for HIV, and users on antiretroviral therapy, exclusion criteria for indication, initiation, and continuity of PrEP use. Also, users who started using PrEP through the "PrEP-Combina! Project", linked to the University of São Paulo Medical School (FMUSP), or who acquired PrEP before December 2017 were excluded from the study since these situations could compromise the data records related to adherence levels after the first month of TDF/ FTC use.

Data collection occurred after the letter of consent was signed by the SES-CE pharmaceutical assistance manager, responsible for managing the system at the state level. The project was approved by the Research Ethics Committees (CEP) of the Universidade Federal do Ceará (UFC opinion no.: 3.644.728/2019) and SES-CE (opinion no.: 3.765.612/2019). Thus, data were collected from the first care records and the 30-, 90-, and 180-day PrEP clinical follow-ups.

To measure the degree of adherence of individuals, we used part of the method described in the works by Montgomery et al. ${ }^{13}$ which consisted of analyzing the self-report of the use of TDF/FTC by the user by completing the PrEP monitoring form in SICLOM by the professional health, which allowed us to assess the adherence behavior of users by the frequency with which they stop taking the medication. Additionally, to measure the level of adherence of subjects to PrEP, the following scale was adopted: ' $\leq 79 \%$ unsatisfactory adherence', ' $\geq 80 \%$ ideal adherence' and ' $=100 \%$ full adherence'.

The data obtained were tabulated in Microsoft Excel ${ }^{\circledR}$, version 2016, and the statistical analysis of the results was performed in the Statistic Package for Social Sciences $\left(\right.$ SPSS $\left.^{\circledR}\right)$, version 22 . The results were presented through descriptive and inferential analysis, using graphs, tables, frequency, mean and standard deviation.

Categorical variables were used for the bivariate analysis. The association between outcome (adherence) and exposure (sociodemographic characteristics and risk behavior for HIV infection) variables was determined by a $p$-value less than $5 \%(p<0.05)$ and a $95 \%$ confidence interval $(95 \% \mathrm{CI})$.

The outcome variables (dependent) were adherence $=100 \%$ and adherence $<100 \%$. The causal (independent) variables were as follows: Age; provenance; education; genital organ of birth; sexual orientation; gender identity; race/color; PEP use in the past 12 months; the number of sexual partners in the past six months; condom use in the past three months; sexual intercourse with PLHIV in the past six months; sex in exchange for money, drugs, or housing; STI symptoms/diagnosis in the past six months; reproductive planning; alcohol use; and illicit drug use. Those with significance less than or equal to 0.20 were included for the logistic regression models based on factors that could interfere with the full adherence to PrEP. The condition of significance less than or equal to 0.05 remained in the final model.

\section{RESULTS}

The analyses returned a registry of 412 individuals using PrEP. Of these, $231(56.1 \%)$ comprised the study sample, given that 117 subjects had no data from the first clinical monitoring of PrEP since they participated in the "PrEP-COMBINA! Project" of the FMUSP, and 64 individuals, because they had not yet registered in SICLOM the third clinical monitoring of PrEP. Most participants were male $(80.1 \% ; n=185)$, homosexual (61.9\%; $n=143)$, brown (57.6\%; $n=133)$, living in Fortaleza $(78.4 \% ; n=181)$, and with a mean age of $32 \pm 8.6$ years (range $19-62$ years), where the age range $21-40$ years was prevalent $(80.5 \% ; n=186)$. Other characteristics of the individuals studied are shown in Table 1.

The mean time of PrEP use at the time of data collection was $15 \pm 5.9$ months, ranging from 7 to 46 months. We should note that before using PrEP, $42.9 \%$ ( $n=99)$ of the subjects had used PEP in the past 12 months, with some individuals $(2.6 \%$; $n=6)$ using it more than four times during that period. Regarding the decision to use the method, 66.7\% ( $n=154)$ of users were sensitized through communication, such as television and the internet; $24.2 \%(n=56)$ were referred to by a health professional, and 9.1\% $(n=21)$ were referred by Non-Governmental Organizations (NGO).

Regarding clinical aspects and potential exclusion criteria for the use of the method, it was observed that $4.8 \%(n=11)$ had a history of chronic kidney disease, and 50.2\% ( $n=116)$ had not completed the hepatitis B vaccination scheme, only $42.4 \%(n=98)$ of these were referred for vaccination. In addition, $100 \%(n=231)$ of the subjects denied having suffered a bone fracture unrelated to trauma, and $12.1 \%(n=28)$ reported using injectable drugs without medical recommendations. Rapid HIV testing was performed in $100 \%(n=231)$ of the subjects to rule out a previous infection.

The PrEP monitoring tests revealed that a significant portion of individuals did not perform them at the 30 and 180-day monitoring follow-up, since they should be performed quarterly and/or semiannually, according to the PCDT-PrEP recommendations, such as the non-treponemal test for syphilis $(75.3 \% ; n=174 / 75.8 \% ; n=175)$, research for chlamydia $(97.0 \%$; $n=224 / 96.1 \% ; n=222)$ and gonococcus $(97.0 \% ; n=224 / 95.2 \% ; n=220)$. Considering the same period, it was also observed that there was no positivity in rapid HIV tests and the increase of positive results in nontreponemal syphilis tests, which went from $8.2 \%(n=19)$ to $13.4 \%(n=31)$. The results of the other PrEP monitoring tests can be seen in Table 2.

Regarding the sexual behavior of PrEP users in the face of a possible increase in the number of sexual partners, it was found that there was 
Table 1: Socio-demographic characteristics of the study participants. Ceará, 2020.

\begin{tabular}{|c|c|c|}
\hline & $n$ & $\%$ \\
\hline \multicolumn{3}{|l|}{ Genital organ of birth } \\
\hline Penis & 185 & 80,1 \\
\hline Vagina & 46 & 19,9 \\
\hline \multicolumn{3}{|l|}{ Color/race } \\
\hline Yellow & 2 & 0,9 \\
\hline White & 77 & 33,3 \\
\hline Brown & 133 & 57,6 \\
\hline Black & 19 & 8,2 \\
\hline \multicolumn{3}{|l|}{ Age group (years) } \\
\hline $0-20$ & 1 & 0,4 \\
\hline $21-40$ & 186 & 80,5 \\
\hline $41-60$ & 42 & 18,2 \\
\hline $61-80$ & 2 & 0,9 \\
\hline \multicolumn{3}{|l|}{ Sexual orientation } \\
\hline Man & 185 & 80,1 \\
\hline Woman & 43 & 18,6 \\
\hline Transvestite woman & 3 & 1,3 \\
\hline \multicolumn{3}{|l|}{ Gender Identity } \\
\hline Heterosexual & 67 & 29,0 \\
\hline Homosexual & 143 & 61,9 \\
\hline Bisexual & 21 & 9,1 \\
\hline \multicolumn{3}{|l|}{ Education } \\
\hline No & 2 & 0,9 \\
\hline $4-7$ years old & 10 & 4,3 \\
\hline 8-11 years old & 65 & 28,1 \\
\hline 12 years and older & 154 & 66,7 \\
\hline \multicolumn{3}{|l|}{ City of residence } \\
\hline Fortaleza & 181 & 78,4 \\
\hline Caucaia & 9 & 3,9 \\
\hline Maracanaú & 6 & 2,6 \\
\hline Other* & 35 & 15,1 \\
\hline
\end{tabular}

Source: Research data - MS/SICLOM/SESA-CE (2020)

$\mathrm{n}=$ Relative frequency

$\%=$ Absolute frequency

* Atalaia (Alagoas); Barreira; Beberibe; Camocim; Chorozinho; Iguatu; Itaitinga; Morada Nova; Natal (Rio Grande do Norte); Pacajus; Pacatuba; Paracuru; Parambu; Pedra Branca; Pentecoste; Quixadá, Redenção; Santo André (São Paulo); São Paulo (São Paulo); Sobral; Tabuleiro do Norte; Uruburetama.

no statistically significant difference in the average number of sexual partners at the beginning of the study $(10.86 \pm 49.72)$ to $90(11.32 \pm 46.28)$ or $180(12.20 \pm 48.79)$ days later.

Still in this context, the use of condoms by individuals and the acquisition of STI after the beginning of PrEP until the third monitoring was investigated. Under these aspects, there was a significant increase in individuals not using condoms in any sexual relations $(p=0.001)$ (Figure 1). However, there were no significant changes $(p=0.769)$ in STI prevalence when comparing the analyzed periods.
Table 2: Results of the monitoring tests of pre-exposure prophylaxis to HIV recorded in the logistic control system of medicines regarding users' 30 and 180-day follow-up using the method. Ceará, 2020.

\begin{tabular}{|c|c|c|c|c|}
\hline \multirow[t]{2}{*}{ Prep Monitoring Exams } & \multicolumn{2}{|c|}{$\begin{array}{c}\text { Follow-up } 30 \\
\text { days }\end{array}$} & \multicolumn{2}{|c|}{$\begin{array}{l}\text { Follow-up } \\
180 \text { days }\end{array}$} \\
\hline & $\mathbf{N}$ & $\%$ & $\mathbf{N}$ & $\%$ \\
\hline \multicolumn{5}{|c|}{ Syphilis rapid test (treponemal test) } \\
\hline Non-reactive & 151 & 65.4 & 164 & 71.0 \\
\hline Not performed & 61 & 26.4 & 36 & 15.6 \\
\hline Reagents & 19 & 8.2 & 31 & 13.4 \\
\hline \multicolumn{5}{|l|}{ Non-treponemal test for syphilis } \\
\hline Not performed & 174 & 75.3 & 175 & 75.8 \\
\hline Non-reactive & 51 & 22.1 & 41 & 17.7 \\
\hline Reagent & 6 & 2.6 & 15 & 6.5 \\
\hline \multicolumn{5}{|l|}{ Hepatitis $B$ rapid test } \\
\hline Non-reactive & 208 & 90.0 & 183 & 79.2 \\
\hline Not performed & 21 & 9.1 & 48 & 20.8 \\
\hline Reagent & 2 & 0.9 & 0 & 0 \\
\hline \multicolumn{5}{|l|}{ Anti-HBsAg serology } \\
\hline$>10 \mathrm{UI} / \mathrm{ml}$ & 128 & 55.4 & 143 & 61.9 \\
\hline$<10 \mathrm{UI} / \mathrm{ml}$ & 63 & 27.3 & 1 & 0.4 \\
\hline Not performed & 40 & 17.3 & 87 & 37.7 \\
\hline \multicolumn{5}{|l|}{ Hepatitis $\mathrm{C}$ rapid test } \\
\hline Non-reactive & 225 & 97.4 & 216 & 93.5 \\
\hline Not performed & 6 & 2.6 & 15 & 6.5 \\
\hline Reagent & 0 & 0 & 0 & 0 \\
\hline \multicolumn{5}{|l|}{ Identification of chlamydia } \\
\hline Not performed & 224 & 97.0 & 222 & 96.1 \\
\hline Non-reactive & 7 & 3.0 & 4 & 1.7 \\
\hline Reagent & 0 & 0 & 5 & 2.2 \\
\hline \multicolumn{5}{|l|}{ Identification of gonococcus } \\
\hline Not performed & 224 & 97.0 & 220 & 95.2 \\
\hline Non-reactive & 7 & 3.0 & 6 & 2.6 \\
\hline Reagent & 0 & 0 & 5 & 2.2 \\
\hline \multicolumn{5}{|l|}{ Assessment of proteinuria } \\
\hline Normal & 182 & 78.8 & 183 & 79.2 \\
\hline Changed & 34 & 14.7 & 12 & 5.2 \\
\hline Not performed & 15 & 6.5 & 36 & 15.6 \\
\hline \multicolumn{5}{|l|}{ Creatinine } \\
\hline$>60 \mathrm{ml} / \mathrm{min}$ & 223 & 96.5 & 208 & 90.0 \\
\hline Not performed & 8 & 3.5 & 22 & 9.5 \\
\hline$<60 \mathrm{ml} / \mathrm{min}$ & 0 & 0 & 1 & 0.4 \\
\hline \multicolumn{5}{|l|}{ HIV rapid test } \\
\hline Non-reactive & 231 & 100 & 231 & 100 \\
\hline Reagent & 0 & 0 & 0 & 0 \\
\hline Not performed & 0 & 0 & 0 & 0 \\
\hline
\end{tabular}

Source: Research data - MS/SICLOM/SESA-CE (2020)

SIGLS: HIV - Acquired Immunodeficiency Virus; HBsAg - Hepatitis B virus surface antigen. 


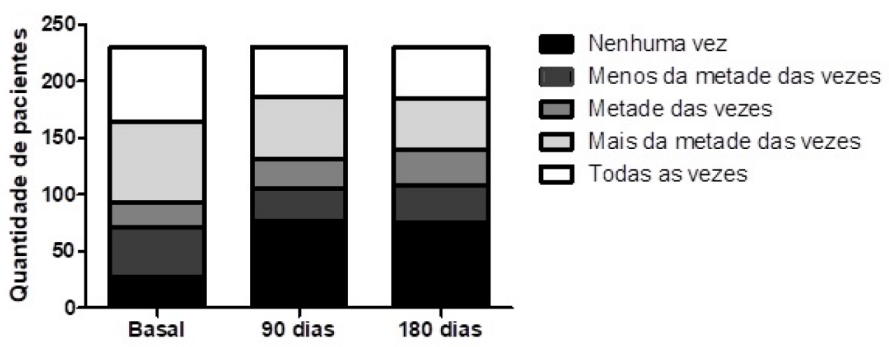

Figure 1: Condom use by users three months before HIV pre-exposure prophylaxis and after 90 and 180 days in the use of the method. Ceará, 2020. $p<0.001$, Pearson's chi-square test.

Source: Research data - MS/SICLOM/SESA-CE (2020)

The degree of adherence of subjects to PrEP, considering the sum of the three periods, was $95.36 \pm 7.15 \%$ (range $=62.22-100 \%$ ) (Figure 2), of which $5.6 \%(n=13)$ had adherence $\leq 79 \%$ (unsatisfactory), $87.0 \%(\mathrm{n}=201)$ $\geq 80 \%$ (ideal adherence) and $7.4 \%(n=17)=100 \%$ (full adherence).

Concerning possible causes that could interfere with full adherence to TDF/FTC, it was observed in the bivariate analysis that variables such as sexual practice in exchange for money, drugs, or housing $(p=0.033)$, and gender identity $(p=0.049)$ had a statistically significant association with the degree of adherence to the method. Moreover, other investigated characteristics showed no association with 'full adherence' to PrEP (Table 3). However, multinomial logistic regression only indicated the presence of an association between symptoms/diagnosis of STI and the degree of adherence to PrEP, where it was possible to observe that this condition is inversely proportional to full adherence to the method $(p=0.013$; adjusted OR $(95 \% \mathrm{CI})=4.38(1.36-14.13)$.

\section{DISCUSSION}

In Brazil, the HIV/AIDS epidemic is concentrated in some population segments that account for most new cases of infection, such as gay men and men who have sex with other men, transgender people, and sex workers. However, in addition to being at higher risk of acquiring HIV, these people are often subject to discrimination, being targets of stigma and prejudice, thus increasing their vulnerability to HIV/AIDS. ${ }^{14}$

For these cases, PrEP is inserted as an additional prevention strategy available at SUS to reduce HIV transmission and contribute to achieving goals related to the end of the epidemic. ${ }^{8}$ Under these aspects, it was observed that the users studied were primarily young adults, brown and white, residents of the capital (Fortaleza) and metropolitan region, with an education level of 12 or more. These results contrast with Huang et al. (2018), ${ }^{15}$ which studied PrEP adherence in an HIV care provider in the United States. However, it is worth drawing attention to a portion of the MSM population, which could also benefit from the use of PrEP; however, they apparently do not have the same access as the others, such as the black population and those with low education, either due to misinformation regarding the provision of the method or the difficulty in accessing health services. ${ }^{16}$ Above all, socioeconomic and cultural factors, stigmas related to sexuality, no concept of preventive care, and lack of risk perception are conditions that can distance people from other methods of protection against HIV. ${ }^{17}$

Considering this context, the media, such as the internet, were the primary vehicles that led individuals to seek PrEP. The access to a plethora of information sources available on the internet play a key role in shaping this active posture of the individual who decides to expand his prevention strategies for HIV. ${ }^{18}$

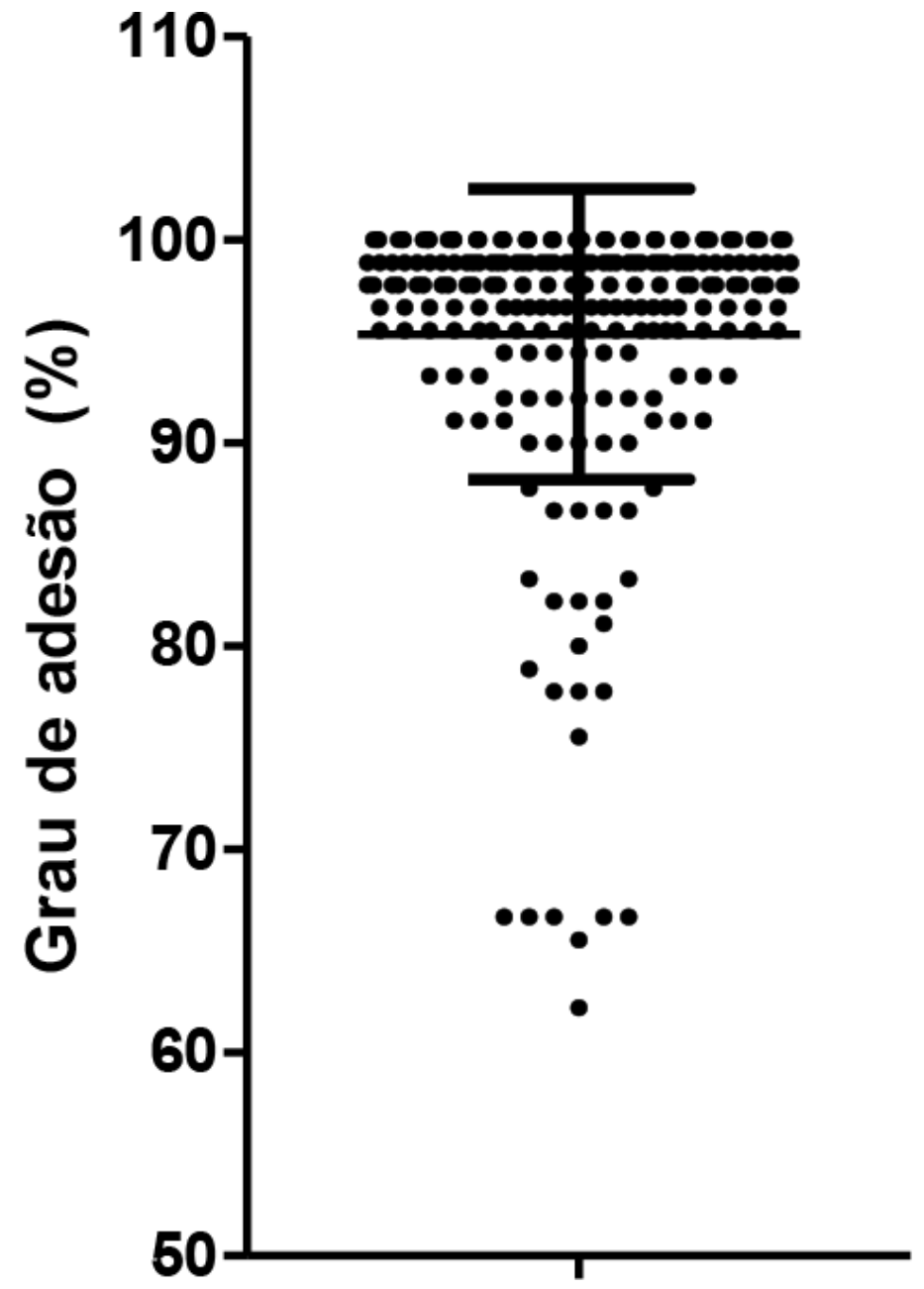

Figure 2: Graph representing the degree of adherence of users of pre-exposure prophylaxis to HIV. Ceará, 2020.

Source: Research data - MS/SICLOM/SESA-CE (2020)

However, the search for information over the internet about PrEP may be a worrying factor since a study conducted in China by Han et al. $(2018)^{19}$ pointed out that survey participants preferred information obtained over the internet about using TDF/FTC than from specialized services. This condition may favor self-medication through clandestine drug purchases since PrEP drugs are dispensed in Brazil exclusively by SUS.

One result that drew attention was the presence of individuals with chronic kidney disease. The clinical protocol and therapeutic guidelines for managing HIV/AIDS in adults recommend that PLHIV with kidney damage who will start antiretroviral therapy have TDF, one of the antiretroviral drugs that constitute the first-line regimen, replaced for the other nucleotide-analog reverse-transcriptase inhibitor. ${ }^{20}$ The presence of kidney damage in PrEP candidates is one of the potential criteria for their exclusion; however, it is up to the prescribing professional to evaluate the risk-benefit ratio. Mostly, Sales and Foresto recommend frequent monitoring of renal function and tubular damage markers, such as glycosuria and phosphaturia (tests not listed in the PCDT-PrEP), and its suspension in patients with a $25 \%$ reduction in baseline GFR or when $<60 \mathrm{~mL} / \mathrm{min} / 1.73 .{ }^{21}$ Also, according to the authors, one of the strategies to improve drug tolerability is the replacement of tenofovir disoproxil fumarate with the prodrug tenofovir alafenamide, already approved in Brazil for the treatment of HBV, replacing the TDF of PrEP, since it produces less renal toxicity. ${ }^{21}$ 
Table 3: Association analysis between the degree of adherence to HIV pre-exposure prophylaxis and sociodemographic data and risk factors for HIV infection of PrEP method users. Ceará, 2020.

\begin{tabular}{|c|c|c|c|c|}
\hline & \multicolumn{4}{|c|}{$\begin{array}{c}\text { Degree of adherence to } \\
\text { PrEP }\end{array}$} \\
\hline & Total & $<100 \%$ & $100 \%$ & $\mathrm{p}$-Value \\
\hline \multicolumn{5}{|l|}{$\begin{array}{c}\text { Sociodemographic } \\
\text { data }\end{array}$} \\
\hline \multicolumn{5}{|l|}{ Age } \\
\hline Up to 30 & $103(44.6 \%)$ & $81(46.6 \%)$ & $22(38.6 \%)$ & 0.294 \\
\hline$>30$ & $128(55.4 \%)$ & $93(53.4 \%)$ & $35(61.4 \%)$ & \\
\hline \multicolumn{5}{|l|}{ Source } \\
\hline Countryside & $48(20.8 \%)$ & $35(20.1 \%)$ & $13(22.8 \%)$ & 0.664 \\
\hline Fortaleza & $183(79.2 \%)$ & $139(79.9 \%)$ & $44(77.2 \%)$ & \\
\hline \multicolumn{5}{|l|}{ Education } \\
\hline Up to 7 years & $11(4.8 \%)$ & $7(4.0 \%)$ & $4(7.0 \%)$ & 0.183 \\
\hline \multicolumn{5}{|l|}{ Between 8 -11 years } \\
\hline 12 years and older & $155(67.1 \%)$ & $113(64.9 \%)$ & $42(73.7 \%)$ & \\
\hline \multicolumn{5}{|l|}{$\begin{array}{l}\text { Genital organ } \\
\text { birth }\end{array}$} \\
\hline Penis & $185(80.1 \%)$ & $138(79.3 \%)$ & $47(82.5 \%)$ & 0.606 \\
\hline Vagina & $46(19.9 \%)$ & $36(20.7 \%)$ & $10(17.5 \%)$ & \\
\hline \multicolumn{5}{|l|}{ Sexual orientation } \\
\hline Woman & $46(20.0 \%)$ & $36(20.8 \%)$ & $10(17.5 \%)$ & 0.593 \\
\hline Man & $184(80.0 \%)$ & $137(79.2 \%)$ & $47(82.5 \%)$ & \\
\hline \multicolumn{5}{|l|}{ Gender Identity } \\
\hline Heterosexual & $63(27.3 \%)$ & $49(28.2 \%)$ & $14(24.6 \%)^{*}$ & 0.049 \\
\hline Homosexual & $147(63.6 \%)$ & $105(60.3 \%)^{*}$ & $42(73.7 \%)$ & \\
\hline Bisexual & $21(9.1 \%)$ & $20(11.5 \%)$ & $1(1.8 \%)$ & \\
\hline \multicolumn{5}{|l|}{ Race } \\
\hline Brown & $11(4.8 \%)$ & $7(4.0 \%)$ & $4(7.0 \%)$ & 0.283 \\
\hline Black & $65(28.1 \%)$ & $54(31.0 \%)$ & $11(19.3 \%)$ & \\
\hline \multirow[t]{2}{*}{ Yellow } & $155(67.1 \%)$ & $113(64.9 \%)$ & $42(73.7 \%)$ & \\
\hline & \multicolumn{4}{|c|}{ Risk factors for HIV infection } \\
\hline \multicolumn{5}{|l|}{$\begin{array}{l}\text { PEP use in the last } \\
12 \text { months }\end{array}$} \\
\hline No & $132(57.1 \%)$ & $102(58.6 \%)$ & $30(52.6 \%)$ & 0.428 \\
\hline Yes & $99(42.9 \%)$ & $72(41.4 \%)$ & $27(47.4 \%)$ & \\
\hline \multicolumn{5}{|l|}{$\begin{array}{l}\text { Number of sexual } \\
\text { partners } 6 \text { months }\end{array}$} \\
\hline Up to 2 & $141(61.0 \%)$ & $106(60.9 \%)$ & $35(61.4 \%)$ & 0.948 \\
\hline$>2$ & $90(39.0 \%)$ & $68(39.1 \%)$ & $22(38.6 \%)$ & \\
\hline \multicolumn{5}{|l|}{$\begin{array}{c}\text { Condom use last } 3 \\
\text { months }\end{array}$} \\
\hline No time & $28(12,2 \%)$ & $21(12,1 \%)$ & $7(12,5 \%)$ & 0,609 \\
\hline $\begin{array}{l}\text { Less than half the } \\
\text { time }\end{array}$ & $43(18,7 \%)$ & $35(20,1 \%)$ & $8(14,3 \%)$ & \\
\hline Half of the time & $22(9,6 \%)$ & $14(8,0 \%)$ & $8(14,3 \%)$ & \\
\hline $\begin{array}{l}\text { More than half of } \\
\text { the time }\end{array}$ & $71(30,9 \%)$ & $55(31,6 \%)$ & $16(28,6 \%)$ & \\
\hline Every Time & $66(28,7 \%)$ & $49(28,2 \%)$ & $17(30,4 \%)$ & \\
\hline
\end{tabular}

\section{Relationship without a condom last 6 months}

Anal receptive $102(45,3 \%) \quad 77(45,6 \%) \quad 25(44,6 \%) \quad 0,905$

Vaginal insertive $23(10,2 \%) \quad 17(10,1 \%) \quad 6(10,7 \%) \quad 0,888$

Vaginal receptive $\quad 43(19,1 \%) \quad 34(20,1 \%) \quad 9(16,1 \%) \quad 0,504$

Sexual intercourse in the last 6 months with PLHIV

$\begin{array}{ccccc}\text { No } & 57(24,7 \%) & 48(27,6 \%) & 9(15,8 \%) & 0,184 \\ \text { I don't know } & 54(23,4 \%) & 38(21,8 \%) & 16(28,1 \%) & \\ \text { Yes } & 120(51,9 \%) & 88(50,6 \%) & 32(56,1 \%) & \end{array}$

In the last 6 months, you had sex in exchange for money, drugs, etc.

$\begin{array}{lcccc}\text { No } & 211(91,3 \%) & 155(89,1 \%) & 56(98,2 \%)^{*} & 0,033 \\ \text { Yes } & 20(8,7 \%) & 19(10,9 \%)^{*} & 1(1,8 \%) & \end{array}$

Symptom/diagnosis of STI in the last 6 months

\begin{tabular}{lcrrr} 
No & $181(78,4 \%)$ & $132(75,9 \%)$ & $49(86,0 \%)$ & 0,108 \\
Yes & $50(21,6 \%)$ & $42(24,1 \%)$ & $8(14,0 \%)$ & \\
\multicolumn{5}{c}{ Reproductive Planning } \\
No & $203(87,9 \%)$ & $153(87,9 \%)$ & $50(87,7 \%)$ & 0,966 \\
Yes & $28(12,1 \%)$ & $21(12,1 \%)$ & $7(12,3 \%)$ &
\end{tabular}

Alcohol Use

$\begin{array}{lcccc}\text { No } & 96(41,6 \%) & 68(39,1 \%) & 28(49,1 \%) & 0,182 \\ \text { Yes } & 135(58,4 \%) & 106(60,9 \%) & 29(50,9 \%) & \end{array}$

Drug Use

No $\quad 157(68,0 \%) \quad 121(69,5 \%) \quad 36(63,2 \%) \quad 0,370$

Yes $\quad 74(32,0 \%) \quad 53(30,5 \%) \quad 21(36,8 \%)$

Amount of drugs

used

No $\quad 158(68,7 \%) \quad 122(70,1 \%) \quad 36(64,3 \%) \quad 0,498$

A $\quad 45(19,6 \%) \quad 34(19,5 \%) \quad 11(19,6 \%)$

Two or more

$27(11,7 \%) \quad 18(10,3 \%) \quad 9(16,1 \%)$

${ }^{*} p<0.05$, Fisher's exact test or Pearson's chi-square test ( $\left.\mathrm{n}, \%\right)$.

Source: Research data - MS/SICLOM/SESA-CE (2020)

STI - Sexually transmitted infection; PLHIV - People living with HIV.

One of the challenges for the implementation of PrEP in health institutions is the monitoring of PrEP users since they must provide a set of care services that need to be provided to the subjects, ranging from emergency care in the face of possible complications related to the use of drugs, and the provision of laboratory tests, since the need for monitoring of clinical conditions of individuals. ${ }^{8}$ In this aspect, it was notable the percentage of subjects who failed to perform, at some point, monitoring tests recommended by the PCDT-PrEP. ${ }^{8}$ This situation is worrisome because PrEP users may be unassisted of care or without access to health care, especially concerning liver and kidney changes and the acquisition of STI, which usually manifest late, preventing early treatment and enabling the transmission to other sexual partners.

Above all, it is worth noting the slight increase in the positivity of the rapid syphilis test between the 30 and 180-day follow-up visits. This increase reinforces the need to use other prevention methods, such as condoms, taking into account the recommendations of the $\mathrm{MH}^{8}{ }^{8}$ In addition, the number of users immunized for $\mathrm{HBV}$, which increased $6.5 \%(n=15)$ in the 180-day interval, stands out as a positive point. 
Moreover, concerning the other risk behaviors for HIV infection, this research showed that the number of sexual partnerships of PrEP users remained stable in the second and third monitoring compared to the initial registration of the subjects in SICLOM. However, a reduction in condom use was observed in all sexual relationships in the period analyzed. According to Di Ciaccio et al. (2019), ${ }^{22}$ theories of rational action and planned behavior may partially explain the results achieved since they show that factors other than risk perception can predict condom use. ${ }^{22}$ In fact, according to the authors, condom use is influenced by intention to use, subjective attitudes and norms toward condoms, and, to a lesser extent, the associated perceived behavioral control. ${ }^{22,23}$

In parallel, no increase in STI prevalence was observed. This concern was related to the phenomenon of risk compensation or behavioral disinhibition, in which PrEP users' perception of reduced risk of HIV acquisition could lead them to engage in riskier sexual practices and thus increase their chances of acquiring STI ${ }^{24}$ However, it was observed that there was no statistically significant difference regarding the possible increase in sexual partnerships and STI, which contradicts the results obtained by Nguyen (2018), wherein a retrospective cohort study including PrEP users followed up for 12 months in Montreal - Canada, he observed increased STI rates among individuals after starting PrEP, which may suggest greater risk behaviors during the first year of using the method. ${ }^{25}$

Regarding the individuals' use of TDF/FTC, the wide adherence to the method was notorious, considering that the overall average adherence in the three study periods was higher than $95 \%$. This finding was very positive since the effectiveness of PrEP is closely related to its adherence. ${ }^{12}$ Regarding the determinants for not using $100 \%$ of the recommended doses, bivariate and multivariate analyses revealed that factors such as gender identity, sexual practice in exchange for money, drugs or housing, and STI infections influenced full adherence to PrEP. Thus, qualitative research conducted in Lima, the capital of Peru, with MSM, gay men, and sex workers, pointed out as a potential failure in adherence to the users' distrust of the safety of PrEP drugs, added to economic, sociocultural, and political factors. ${ }^{26}$

Especially for PrEP users affected by STI, who had difficulty adhering to PrEP, this result is worrisome since STI are the gateway to HIV, especially those not adherent to condoms (BRASIL, 2017). Given this, it is necessary to strengthen adherence and health education strategies by professionals since it is essential to ensure efficiency in using PrEP by improving adherence among beneficiaries. The literature points out that if users do not adhere to the drugs at the end of the entire care process, the entire health system fails, and the investments intended for this purpose can be considered inefficient. ${ }^{27}$

As the limitation of this work, we can mention the impossibility of conducting a research study in the physical records of the services due to the current guidelines of the 2019 Coronavirus pandemic (SARS-CoV-2; COVID-19). However, the research was adapted to achieve representative results through the information system. It is believed that the medical records contain privileged information, which could contribute further richness of data, which may be the focus of future research.

We hope that the results achieved will alert health professionals to the need to reinforce aspects such as adherence, especially in the groups that had the most difficulty, and establish measures to improve the reach of this strategy to ensure effectiveness and access prophylaxis.

\section{CONCLUSION}

Our findings indicated high adherence to PrEP. This result may be related to the level of education and young age of the participants. However, we observed that factors such as homosexuality, STI diagnosis, sexual practice in exchange for money, illicit drugs, or housing had a negative association concerning wide adherence to prophylaxis. Furthermore, it is necessary to monitor these individuals by a multi-professional team to follow them expressively and systematically, avoid complications related to the use of the method, and identify STI and even HIV infections early. The results achieved can support the comprehensive care of PrEP users since it allows them to know their characteristics and habits at risk for HIV infection, among other determinants and associated factors.

\section{ACKNOWLEDGEMENT}

The authors acknowledge the Secretariat of the State of Ceará to support this study.

\section{CONFLICT OF INTEREST}

The authors declare no conflict of interest.

\section{ABBREVIATIONS}

AIDS: Human Immunodeficiency Syndrome; ARV: antiretrovirals; CEP: Research Ethics Committees; CESAF: Strategic Component of Pharmaceutical Assistance; iPrEx: Pre-exposure Prophylaxis Initiative Trial; COASF: Coordination of Pharmaceutical Assistance; CONITEC: National Committee for Incorporation of Technologies into the Unified Health System; FTC: Emtricitabina; HIV: Human Immunodeficiency Virus; MS: Ministry of Health; MSM: Men who have Sex with Men; NGO: Non-Governmental Organizations; PCDTPrEP: Clinical Protocol and Therapeutic Guidelines for Pre-Exposure Prophylaxis at Risk for HIV Infection; PEP: HIV post-exposure prophylaxis; PLHIV: People Living with HIV; PrEP: Pre-Exposure Prophylaxis; RENAME: National List of Essential and Strategic Medicines; SARS-CoV-2; COVID-19: Coronavirus pandemic 2019; SES-CE: Secretariat of Health of the State of Ceará; SICLOM: System for Logistic Control of Medications; SPSS: Statistic Package for Social Sciences; STI: Sexually Transmitted Infections; SUS: Unified Health System; TDF: Tenofovir; UFC: Universidade Federal do Ceará; UNAIDS: Joint United Nations Programme on HIV/AIDS; WHO: World Health Organization.

\section{REFERENCES}

1. FonnerVA, Dalglish SL, Kennedy CE, Baggaley R, O'Reilly KR, Koechlin FM, et al. Effectiveness and safety of oral HIV preexposure prophylaxis for all populations. AIDS. 2016:30(12):1973-83. doi: 10.1097/QAD.0000000000001145, PMID 27149090, PMCID PMC4949005

2. Eakle R, Venter $F$, Rees H. Pre-exposure prophylaxis (PrEP) in an era of stalled HIV prevention: Can it change the game? Retrovirology. 2018;15(1):29. doi: 10.1186/s12977-018-0408-3, PMID 29609619, PMCID PMC5879931.

3. Stover J, Bollinger L, Izazola JA, Loures L, DeLay P, Ghys PD, Fast Track modeling working group. Correction: What Is Required to End the AIDS Epidemic as a Public Health Threat by 2030? The Cost and Impact of the Fast-Track Approach. PLOS ONEPLOS ONEPLOS ONE. 2019;14(3):e0213970. doi: 10.1371/journal. pone.0213970. PMID 30870508.

4. World Health Organization. Joint United Nations Program on HIV/AIDS. Oral Pre-Expo Prophylaxis-Putting New Choice Context. 2015.

5. Centers for Disease Control and Prevention. Pre-exposure prophylaxis (PrEP) HIV risk and prevention. [citado mar 29 2021]. Available from: https://www.cdc. gov/hiv/risk/prep/index.html.

6. South African National AIDS Programme. South Africa's National strategic plan for HIV, TB, and STIs 2017-2022; 2017 [citado mai 05 2021]. Available from: http://sanac.org.za/wp-content/uploads/2017/05/NSP_FullDocument_ FINAL.pdf.

7. Global advocacy for HIV prevention. Ongoing Plan Prep Demonstration Implement Stud. 2016.

8. Brasil. Ministério da Saúde. Secretaria de Vigilância em Saúde. p. 1-52; 2017. Protocolo Clínico e diretrizes terapêuticas para Profilaxia Pré-Exposição (PrEP) de risco à infecção pelo HIV [citado mai 30 2021]. Available from: http://www. aids.gov.br/pt-br/pub/2017/protocolo-clinico-e-diretrizes-terapeuticas-paraprofilaxia-pre-exposicao-prep-de-risco. 
9. Zucchi EM, Grangeiro A, Ferraz D, Pinheiro TF, Alencar T, Ferguson L, et al. From evidence to action: Challenges for the Brazilian Unified National Health System in offering pre-exposure prophylaxis (PrEP) for HIV to persons with the greatest vulnerability. Cad Saude Publica. 2018;34(7):e00206617. doi: 10.1590/0102311X00206617, PMID 30043853.

10. e Insumos Estratégicos. Brasil. Ministério da Saúde. Secretaria de Ciência Tecnologica. Departamento de Assistência Farmacêutica e Insumos Estratégicos. Relação Nacional de Medicamentos Essenciais: Rename 2020. Ministério da Saúde, Secretaria de Ciência, Tecnologia e Insumos Estratégicos, Departamento de Assistência Farmacêutica e Insumos Estratégicos. 8 ed. Brasília, DF: Ministério da Saúde, 2020. 217 p.

11. Grant RM, Anderson PL, McMahan V, Liu A, Amico KR, Mehrotra M, et al. iPrEx study team. Uptake of pre-exposure prophylaxis, sexual practices, and HIV incidence in men and transgender women who have sex with men: A cohort study. Lancet Infect Dis. 2014;14(9):820-9. doi: 10.1016/S1473-3099(14)70847-3. PMID 25065857, PMCID PMC6107918.

12. Nunn AS, Brinkley-Rubinstein L, Oldenburg CE, Mayer KH, Mimiaga M, Patel R, et al. Defining the HIV pre-exposure prophylaxis care continuum. AIDS. 2017;31(5):731-4. doi: 10.1097/QAD.0000000000001385, PMID 28060019, PMCID PMC5333727.

13. Montgomery MC, Oldenburg CE, Nunn AS, Mena L, Anderson P, LieglerT, et al. Adherence to pre-exposure prophylaxis for HIV prevention in a clinical setting. PLOS ONE. 2016;11(6):e0157742. doi: 10.1371/journal.pone.0157742, PMID 27333000, PMCID PMC4917105.

14. Brasil. BR: Ministério da Saúde, Secretaria de Vigilância em Saúde. Boletim epidemiológico HIV/AIDS ano. p. 1-100; 2015 [citado mai 29 2021]. Available from: http://www.aids.gov.br/sites/default/files/anexos/publicacao/2015/58534/ boletim_aids_11_2015_web_pdf_19105.pdf.

15. Huang M, Liu W, Plomondon ME, Prochazka AV, Bessesen MT. High adherence to HIV pre-exposure prophylaxis among veterans. J Gen Intern Med. 2018;33(3):253-5. doi: 10.1007/s11606-017-4260-2, PMID 29302884, PMCID PMC5834974

16. Werneck J. Racismo institucional e saúde da população negra. Saúde Soc. 2016;25(3):535-49. doi: 10.1590/s0104-129020162610.

17. Okoro ON, Whitson SO. Sexual health, HIV care and pre-exposure prophylaxis in the African immigrant population: A needs assessment. J Immigr Minor Health. 2020;22(1):134-44. doi: 10.1007/s10903-019-00873-x, PMID 30859481.

18. Esher A, CoutinhoT. Rational use of medicines, pharmaceuticalization and uses of methylphenidate Cien Saude Colet. 2017;22(8):2571-80. doi: 10.1590/141381232017228.08622017. PMID 28793073.
19. Han J, Bouey JZ, Wang L, Mi G, Chen Z, He Y, et al. PrEP uptake preferences among men who have sex with men in China: results from a National Internet Survey. J Int AIDS Soc. 2019;22(2):e25242. doi: 10.1002/jia2.25242, PMID 30724470, PMCID PMC6364490.

20. Brasil. BR: Ministério da Saúde, Secretaria de Vigilância em Saúde. Protocolo clínico e diretrizes terapêuticas para manejo da infecção pelo HIV em adultos p. 1-416; 2018 [citado jun 01 2021]. Available from: http://www.aids.gov.br/pt-br/ pub/2013/protocolo- clinico -e- diretrizes-terapeuticas-para-manejo-da-infeccaopelo-hiv-em-adultos.

21. Sales GTM, Foresto RD. Drug-induced nephrotoxicity. Rev Assoc Med Bras (1992). 2020;66Suppl(Suppl 1):s82-90. doi: 10.1590/1806-9282.66.S1.82, PMID 31939540.

22. Di Ciaccio M, Sagaon-Teyssier L, Protière C, Mimi M, Suzan-Monti M, Meyer L, et al. Impact of HIV risk perception on both pre-exposure prophylaxis and condom use. J Health Psychol. 2021;26(10):1575-86. doi: 10.1177/1359105319883927. PMID 31647330.

23. Greene GJ, Andrews R, Kuper L, Mustanski B. Intimacy, monogamy, and condom problems drive unprotected sex among young men in serious relationships with other men: a mixed methods dyadic study. Arch Sex Behav. 2014;43(1):73-87. doi: 10.1007/s10508-013-0210-1, PMID 24202113, PMCID PMC3897392.

24. Blumenthal J, Haubrich $\mathrm{RH}$. Will risk compensation accompany pre-exposure prophylaxis for HIV? Virtual Mentor. 2014;16(11):909-15. doi: 10.1001/ virtualmentor.2014.16.11.stas1-1411, PMID 25397651, PMCID PMC4308722.

25. Nguyen VK, Greenwald ZR, Trottier H, Cadieux M, Goyette A, Beauchemin M, et al. Incidence of sexually transmitted infections before and after preexposure prophylaxis for HIV. AIDS. 2018;32(4):523-30. doi: 10.1097/ QAD.0000000000001718, PMID 29239887, PMCID PMC5865505.

26. Longino A, Montano MA, Sanchez $H$, Bayer A, Sanchez J, Tossas-Milligan $K$ et al. Increasing PrEP uptake and adherence among MSM and TW sex workers in Lima, Perú: what and whom do different patients trust? AIDS Care. 2020:32(2):255-60. doi: 10.1080/09540121.2019.1634787, PMID 31242753, PMCID PMC6988989

27. Meiners M, Tavares NUL, Guimarães LSP, Bertoldi AD, PizzolTSD, Luiza VL, et al. Acesso e adesão a medicamentos entre pessoas com diabetes no Brasil: Evidências da PNAUM. Rev Bras Epidemiol. 2017;20:445-59. doi: 10.1590/19805497201700030008.

Article History: Received: 14-10-2021; Revised: 02-11-2021; Accepted: 23-11-2021

Cite this article: França FÁP, Passos ACB, Medeiros MS, Fonteles MMF. HIV Pre-exposure Prophylaxis: Characterization and Adherence of users at Risk of Infection. J Young Pharm. 2022;14(1):93-9. 